\title{
Células-tronco do líquido amniótico
}

\section{Amniotic fluid stem cells}

\author{
Sergio P. Bydlowski ${ }^{1}$ \\ Adriana A. Debes ${ }^{2}$ \\ Sergio A. Duarte \\ Felipe L. Janz ${ }^{4}$ \\ Rita de Cássia Cavaglieri ${ }^{5}$ \\ Luciana M. F. Maselli ${ }^{6}$
}

\begin{abstract}
Desde o primeiro isolamento e cultivo de células-tronco embrionárias humanas, há mais de 10 anos, seu uso na pesquisa e terapia foi inibida por considerações éticas complexas e pelo risco de transformação maligna destas células indiferenciadas após transplante no paciente. As células-tronco adultas são eticamente aceitas e o risco de transformação maligna é muito baixo. Entretanto, seu potencial de diferenciação e sua capacidade proliferativa são limitados. Cerca de 6 anos atrás, a descoberta de célulastronco no líquido amniótico que expressavam Oct-4, um marcador específico de pluripotencialidade, com alta capacidade de proliferação e diferenciação, iniciou um novo campo promissor na área das células-tronco. Estas células têm potencial de se diferenciar em células dos três folhetos germinativos. Não formam tumores in vivo e não levantam os questionamentos éticos associados com as células-tronco embrionárias humanas. Futuras investigações revelarão se as células-tronco do líquido amniótico realmente irão representar um tipo intermediário com vantagens em relação tanto às células-tronco embrionárias quanto às adultas. Este artigo faz uma revisão acerca destes tópicos e das características biológicas das células-tronco do líquido amniótico. Rev. Bras. Hematol. Hemoter. 2009;31(Supl. 1):45-52.
\end{abstract}

Palavras-chave: Célula-tronco; líquido amniótico; diferenciação celular; marcadores de indiferenciação.

\section{Introdução}

O fluido amniótico humano tem sido utilizado no diagnóstico pré-natal já há mais de 70 anos. $\mathrm{O}$ primeiro relato sobre amniocentese foi em 1930, no qual os autores tentaram correlacionar o número de células presentes no líquido amniótico e o fenótipo celular com o sexo e a saúde do feto. Atualmente, uma das principais utilizações diagnósticas do líquido amniótico é no isolamento de células fetais para cariotipagem, no exame de anormalidades cromossômicas. Recentemente, foram apresentadas evidências de que o líquido amniótico pode ter outras aplicações, além da utiliza- ção como ferramenta diagnóstica. Ele pode ser importante fonte de células terapêuticas para vários distúrbios, tanto congênitos quanto no adulto.

O líquido amniótico contém uma quantidade muito grande de células em suspensão, população celular que é variável com a fase da gestação e que traduz as mudanças na formação do líquido amniótico e da maturação fetal e de seus anexos.

Células-tronco são células precursoras não especializadas, definidas por três critérios principais: habilidade de autorrenovação, capacidade de se diferenciar em múltiplos tipos celulares especializados em resposta a sinais apropria-

${ }^{1}$ Diretor do Laboratório de Genética e Hematologia Molecular, LIM-31, Hospital das Clínicas da FMUSP. Professor Associado de Hematologia e Hemoterapia da Faculdade de Medicina da USP - São Paulo-SP.

${ }^{2}$ Biomédica. Chefe do Departamento de Biologia Celular da Fundação Pró-Sangue, Hemocentro de São Paulo-SP.

${ }^{3}$ Médico. Laboratório de Genética e Hematologia Molecular, LIM-31, Hospital das Clínicas da FMUSP.

${ }^{4}$ Farmacêutico-Bioquímico. Laboratório de Genética e Hematologia Molecular, LIM-31, Hospital das Clínicas da FMUSP.

${ }^{5}$ Biomédica. Laboratório de Genética e Hematologia Molecular, LIM-31, Hospital das Clínicas da FMUSP.

${ }^{6}$ Biomédica. Vice-chefe do Laboratório de Genética e Hematologia Molecular, LIM-31, HC-FMUSP - São Paulo-SP.

Faculdade de Medicina da Universidade de São Paulo (USP) - São Paulo-SP.

Correspondência: Sergio Paulo Bydlowski

Av. Dr. Enéas Carvalho de Aguiar, 155, $1^{\circ}$. andar, sala 43, Divisão de Pesquisa-Cerqueira César

05403-000 - São Paulo-SP - Brasil

Doi: 10.1590/S1516-84842009005000039 
dos, e a habilidade de reconstituição in vivo de um determinado tecido. As células-tronco exibem diferentes graus em sua capacidade de diferenciação.

Um óvulo fertilizado contém células não somente capazes de formar células do mesoderma, endoderma e ectoderma e células germinativas, mas também células do trofoblasto, suporte necessário para a sobrevivência e desenvolvimento do embrião. Assim, pela capacidade de originar todas as células, estas células-tronco são classificadas como totipotentes.

As células-tronco embrionárias e células germinativas embrionárias, isoladas da massa celular interna do blastocisto ou a partir de células germinativas primordiais de um embrião no início de seu desenvolvimento, dão origem ao mesoderma, endoderma e ectoderma, e a células germinativas, mas não a tecidos extraembrionários, e são, por isso, chamadas de pluripotentes. Estas células-tronco geralmente podem ser mantidas em um estado indiferenciado sem perda do potencial de diferenciação, embora possam desenvolver anormalidades cariotípicas quando mantidas em cultura por longos períodos de tempo.

As células-tronco mesenquimais (mesenchymal stem cell - MSC) são consideradas como células multipotentes que possuem potencial para se diferenciar em múltiplas linhagens celulares. Elas geraram uma grande expectativa como fonte potencial de células para o desenvolvimento de estratégias terapêuticas, justamente por sua capacidade intrínseca de autorrenovação e diferenciação. Porém, são uma população rara tanto na medula óssea de um ser humano adulto quanto no cordão umbilical a termo. As MSCs humanas possuem potencial para se diferenciar em múltiplas linhagens incluindo osso, cartilagem, músculo, adipócitos e uma variedade de outros tecidos conjuntivos. Morfologicamente, MSCs em seus estados indiferenciados apresentam formato de espícula, com aspecto fibroblastoide.

Não há graves questões éticas na obtenção de célulastronco hematopoéticas ou mesenquimais adultas, isoladas com facilidade da medula óssea. Porém, estas células, além de serem encontradas em número reduzido, são de difícil expansão contínua. Assim, as células-tronco embrionárias podem dar origem a qualquer tipo celular diferenciado muito mais eficazmente do que células-tronco adultas, que proliferam apenas por um número limitado de gerações e cuja resposta a sinais de diferenciação diminuem a cada geração. A utilização de células-tronco embrionárias, por outro lado, está cercada de inúmeros debates e questões éticas. Talvez uma alternativa adequada às células-tronco embrionárias fosse a utilização de células-tronco mesenquimais de líquido amniótico humano.

\section{Populações celulares do líquido amniótico}

A cultura de células do líquido amniótico humano mostra células com uma ampla gama de morfologias e comporta- mentos. Estas células são variáveis tanto em relação ao tamanho $(6 \mathrm{a} 50 \mu \mathrm{m})$ quanto às formas (escamosas a arredondadas). As populações celulares são heterogêneas, mesmo nos casos de gestações com desenvolvimento fetal normal, e expressam marcadores das três camadas germinativas.

Porém, a maior parte das células está diferenciada terminalmente nas linhagens epiteliais e tem capacidade muito limitada de proliferação e diferenciação. Células epiteliais amnióticas humanas (isoladas a partir da própria membrana amniótica, não a partir do fluido amniótico) possuem capacidade multipotente, aparentemente sendo capazes de se diferenciar em células neurais e da glia, e em precursores de hepatócitos. Estas células têm sido empregadas terapeuticamente em modelos animais de isquemia cerebral e lesão de medula espinal, e como transportadores transgênicos experimentais para o fígado. Contudo, elas não são universalmente consideradas como células do fluido amniótico.

A detecção de certas células progenitoras no fluido amniótico foi inicialmente relatada em 1993, quando células pequenas, com núcleo e arredondadas, identificadas como células progenitoras hematopoéticas, foram encontradas antes da $12^{\mathrm{a}}$ semana de gestação; estas células eram, possivelmente, provenientes da vesícula vitelina. ${ }^{2}$ Em 1996, sugerese a presença de células de linhagem não hematopoética, com potencial multilinhagem, no líquido amniótico, e demonstra-se a conversão miogênica destas células. ${ }^{3}$ Também se confirma a origem fetal das células mesenquimais, coletadas do líquido amniótico e cultivadas in vitro, por meio da tipagem molecular dos antígenos leucocitários humanos (HLA). ${ }^{4}$

Diferentes origens foram sugeridas para a variedade de células presentes no líquido amniótico. Durante toda a gestação ocorre a liberação de diferentes tipos celulares de origem ectodérmica, mesodérmica e endodérmica dependendo principalmente da idade gestacional ou de patologias fetais. Uma subpopulação de células do líquido amniótico foi isolada e mostrou-se capaz de manter a proliferação não diferenciada prolongada, assim como se diferenciar em uma grande gama de tipos celulares, abrangendo as três camadas germinativas. Vários trabalhos sugerem a hipótese de origem mesenquimal de uma parcela de células do líquido amniótico, incluindo a análise de colágeno secretado por essas células, e a constatação de que elas, tanto quanto os fibroblastos expressam HLA classe I (HLA-ABC), mas não a classe II (HLA-DR)..$^{5-8}$

Uma classificação das células do líquido amniótico une critérios morfológicos, bioquímicos e de crescimento celular. ${ }^{9}$ As células do líquido amniótico são provenientes, em sua maior parte, do epitélio e dos tratos digestivo e urinário do feto e do âmnion. As células são classificadas em: tipo E (epitelioides), derivadas da pele e urina fetais; tipo AF (amniotic fluid), específicas do líquido amniótico, que produzem estrógeno, progesterona e gonadotrofina coriônica humana, sendo derivadas do âmnion e do trofoblasto; tipo F (fibroblásticas), derivadas do tecido conjuntivo fetal. ${ }^{10}$ As 
células tipo AF e E aparecem no início da cultura celular enquanto as células tipo $\mathrm{F}$ aparecem posteriormente; porém, somente as células do tipo AF e F persistem com o tempo, enquanto as do tipo E regridem. ${ }^{11}$

No primeiro trimestre de gestação, até a metade do segundo trimestre, o líquido amniótico é formado, em sua maior parte, pelo movimento passivo de água pela membrana amniótica e pele fetal, resultante da difusão simples e do transporte ativo de sódio e cloreto, podendo ser considerado um ultrafiltrado do sangue materno; as células são provenientes, além da descamação de células da vesícula vitelina, do embrião e posteriormente do feto, talvez da placenta e ainda do âmnion..$^{1,12,13-15}$ Entre a $17^{\mathrm{a}}$ e a $20^{\mathrm{a}}$ semana de gestação, ocorre a queratinização da pele fetal, fazendo com que a deglutição e diurese fetais assumam papel importante na formação do líquido amniótico. ${ }^{16}$ De fato, na segunda metade da gestação, a maior parte do fluido provém da urina fetal. Uma importante fonte adicional de fluido amniótico é a secreção proveniente do trato respiratório. ${ }^{17-19}$ As excreções do trato gastrointestinal do feto, conquanto não volumosas, também participam da composição do fluido amniótico. ${ }^{20,21}$ Como resultado desta dinâmica de fluidos, as células presentes nos tratos urinário, respiratório e gastrointestinal podem ser liberadas para o interior da cavidade amniótica; de fato, células desses compartimentos participam do pool celular encontrado no fluido amniótico.

Uma das principais questões levantadas no estudo das células presentes no líquido amniótico foi: o líquido amniótico realmente possuiria células multipotenciais ainda não comprometidas com nenhuma linhagem, ou seja, a mesma célula poderia, dependendo do estímulo, diferenciar-se em células das três linhagens germinativas? Ou seria o líquido amniótico, fonte de células monopotenciais, ou seja, já comprometidas com determinada linhagem, de modo que, sob indução, estas células se diferenciariam somente em linhagens predeterminadas? Vários trabalhos indicam que ambos os tipos celulares existem. Em 2007, por exemplo, pela marcação das células com um vetor retroviral, demonstrou-se que uma única célula podia se diferenciar em seis linhagens diferentes: adipogênica, osteogênica, miogênica, endotelial, neurogênica e hepática. ${ }^{22}$ Por outro lado, em trabalho pioneiro, foi identificado um tipo celular com características de rápida proliferação, com positividade para vimentina, actina de músculo liso (SMA), citoqueratina 8 e 18 e proteína de superfície de fibroblastos (SFP), e negatividade para desmina e CD31; e confirma-se a descendência de linhagem mesenquimal (fibroblástica/miofibroblástica). ${ }^{23,24}$ Foram demonstrados, ainda, precursores neurais e células neuronais diferenciadas, mesmo em gestações em que não ocorre defeito aberto de tubo neural. ${ }^{25}$ Tais células expressam, ao lado de marcadores mesenquimais, outros relacionados a células neuronais, como NES (nestina), TUBB3 (tubulin $\beta$-3), NEFH (neuronal nuclear antigen A60), GALC (galactosilceramidase) e GFAP (glial fibrilary acidic protein $)^{26}$
Inicialmente acreditava-se que as melhores amostras para a obtenção das células-tronco mesenquimais do líquido amniótico (amniotic fluid-mesenchymal stem cell - AFMSC) eram as obtidas no segundo trimestre de gestação. Hoje se sabe que é possível obter AF-MSCs que expressam marcadores de pluripotência em líquido amniótico do terceiro trimestre. Estas células apresentam uma grande capacidade de autorrenovação, expressam o marcador de linhagem celular embrionária (Oct 4) após cultivo in vitro, como veremos adiante, e compartilham as mesmas propriedades $\mathrm{e}$ capacidade de diferenciação de células-tronco embrionárias humanas. Outro comportamento interessante das AFMSCs em relação às células-tronco embrionárias é que, apesar delas formarem corpos embrioides in vitro, que se coram positivamente para marcadores das três camadas germinativas, estas células são incapazes de produzir tumores do tipo teratoma ou teratocarcinoma quando implantadas em camundongos imunodeficientes, o que é comum para as células-tronco embrionárias humanas. ${ }^{22,27}$ Além disto, estas células apresentam baixa antigenicidade, o que é uma grande vantagem para o transplante celular e para a terapia de reposição celular.

Nosso laboratório tem investigado as AF-MSCs humanas in vitro. As células mantêm uma forma arredondada por uma semana após isolamento e cultura em placas não tratadas. Neste estado, possuem uma capacidade de proliferação muito baixa. Após a primeira semana, as células começam a aderir à placa e mudam a morfologia, ficando mais alongadas, e proliferam rapidamente, atingindo $80 \%$ de confluência a cada 48-72 horas, mantendo o cariótipo normal. Foi descrito que as AF-MSCs mantêm o mesmo potencial de expansão por longos períodos, mesmo quando coletadas por ocasião do parto, tornando-se senescentes somente após 27 passagens, correspondente a um período maior que oito meses em cultura. ${ }^{28,29}$ Mantêm a capacidade proliferativa após 32 anos de criopreservação. ${ }^{30}$ Demonstram também capacidade de aderência em bioprótese de polímeros de ácido poliglicólico e derme humana acelular. ${ }^{24}$

As AF-MSCs apresentam maior capacidade de expansão que células-tronco mesenquimais derivadas de outras fontes, como da medula óssea neonatal e de adulto e do cordão umbilical. ${ }^{31,32}$ Enquanto as AF-MSCs atingem o número de 3 milhões de células em nove dias, as MSCs da medula óssea expandem-se para 400 mil células, em condições semelhantes de cultura e plaqueamento. ${ }^{33}$

O fenótipo das AF-MSCs é bastante semelhante às células mesenquimais de outros tecidos, como aquelas originadas da medula óssea e do cordão umbilical. Expressam os antígenos de superfície da membrana celular CD29, CD44, CD90 e CD105. Não expressam CD31, característico de células endoteliais, e CD34 e CD45, característicos de células hematopoéticas. Quanto ao CD73, alguns relatos demonstram expressão nessas células, enquanto outros mostram expressão somente nas células derivadas da medula óssea e não deri- 
vadas de líquido amniótico. ${ }^{11,31-38}$ Esse mesmo padrão imunofenotípico, do tipo mesenquimal, é mantido pelas AF-MSCs após isolamento, expansão, e descongelamento póscriopreservação por cinco meses. ${ }^{39}$

\section{Diferenciação das células-tronco mesenquimais do líquido amniótico}

No líquido amniótico, várias células são identificadas, embora em muito pequeno número ( $1 \%$ das obtidas pela amniocentese), células estas que expressam Oct-4, fator de célula-tronco, vimentina, fosfatase alcalina, SOX-2, Nanog (nanog homeobox), SSEA4 (stage specific embryonic antigen 4), CD34 (cluster differentiation 34), CD105, CD117 e atividade de telomerase, descritos como marcadores de célulastronco embrionárias, embora não exclusivas destas. ${ }^{25,35,40-47}$

A autorrenovação celular é um processo importante para a manutenção da pluripotência das células-tronco. Ela confere a algumas células a capacidade de se dividir, mantendo seu estado de indiferenciação, tanto pela divisão celular simétrica, como assimétrica. ${ }^{48}$ A regulação da capacidade de autorrenovação destas células é feita por genes cujos produtos interferem na própria expressão gênica. ${ }^{49}$ Estes genes, que são expressos quase exclusivamente nos estágios iniciais do desenvolvimento embrionário ${ }^{50}$ são: os genes da família SOX, mais de 11 já descritos, embora neste contexto o mais importante seja o SOX-2, que codifica uma proteína não histônica capaz de se ligar ao DNA, influenciando, positiva ou negativamente, a expressão de determinados genes $;{ }^{51} \mathrm{o}$ Oct-4, que participa de duas etapas cruciais na formação do embrião; a primeira, na etapa da formação da mórula com desenvolvimento da massa celular interna, que é pluripotente, e do trofoectoderma; e a segunda, no estágio de pré-implantação, com formação do epiblasto pluripotente e do ectoderma primitivo $^{52}$; e, finalmente, o Nanog, que talvez seja o mais importante deles, pois atua, principalmente, mantendo a capacidade de autorrenovação destas células e o seu estado indiferenciado. ${ }^{53} \mathrm{O}$ produto do gene Oct-4 não é necessário para a expressão do gene Nanog, porém o Nanog não pode atuar na ausência de Oct-4. ${ }^{52}$

Inicialmente descrito por Scholer, o Oct-4 foi o primeiro gene identificado como regulador mestre da pluripotência..$^{54,55}$ É descrito como uma proteína de ligação do DNA, do homodomínio POU, codificado por 324 aminoácidos ORF55. O Oct-4 depende de dois domínios de transativação no DNA para exercer suas atividades de transcrição. ${ }^{56}$ É sintetizado e transportado para o núcleo por meio do NLS (nuclear localization signal). ${ }^{57} \mathrm{O}$ NLS do Oct-4 é necessário para a atividade de transcrição, sem o qual ocorre diferenciação das células-tronco embrionárias. ${ }^{57} \mathrm{O}$ padrão de expressão do Oct4 sugere que ele pode regular as características celulares do desenvolvimento embrionário inicial..$^{55}$

Em conclusão, os transcritos Oct-4, Nanog e o SOX-2 exercem um papel essencial e coordenado, bloqueando genes

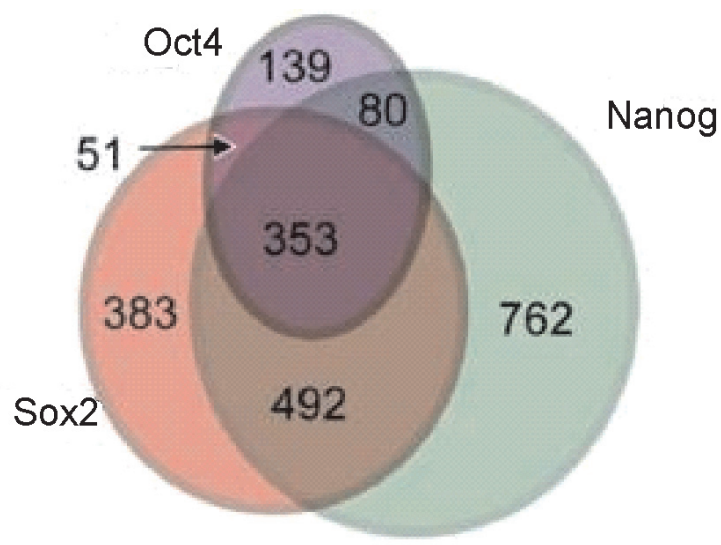

Figura 1. Diagrama de Venn mostrando o número de genes regulados por Sox2, Oct4 e Nanog, individualmente e em interação, em células indiferenciadas. Baseado em http://jura.wi.mit.edu/young_ public/hESregulation/Target_genes.html

que, na ausência dos transcritos, desencadeiam diferenciação. ${ }^{54,58-62}$ Confirmam-se estes dados pela demonstração da reprogramação de células diferenciadas adultas ao estado de pluripotência pela introdução dos fatores de pluripotência Oct-4 e SOX-2 nas mesmas, por meio da técnica iPS (induced pluripotent stem cells). ${ }^{62-65}$

A interação destes genes na expressão gênica das células-tronco esta mostrada na Figura 1. Note-se que estes três genes, isolados ou em associação entre eles, são responsáveis pela expressão de mais de 2.000 outros genes envolvidos nos processos de autorrenovação e de manutenção da plasticidade e pluripotência das células-tronco. ${ }^{66}$

O fenótipo de amniócitos mesenquimais humanos expandidos em cultura é similar ao relatado para células-tronco mesenquimais derivadas de tecido fetal do segundo trimestre de gestação e medula óssea de adulto. As AF-MSCs humanas podem diferenciar-se em uma ampla gama de células. Amniócitos mesenquimais humanos apresentam potencial de diferenciação multilinhagem em fibroblastos, adipócitos e osteócitos, inclusive após exposição a condições específicas de cultura.

As Figuras 2, 3 e 4 mostram a diferenciação condrogênica, osteogênica e neurogênica, respectivamente, de células de líquido amniótico humano obtido na $20^{\mathrm{a}}$ semana de gestação, em cultura.

Estudos de diferenciação mostram que a cartilagem originada das AF-MSCs é a que mais se aproxima da cartilagem fetal original, com maior quantidade de glicosaminoglicanos, matriz extracelular e elastina, quando comparada com células derivadas das células mesenquimais de medula óssea e cordão umbilical, embora tenha menor quantidade de colágeno tipo II que aquela de origem fetal. ${ }^{32,67}$

Em outro relato, AF-MSCs humanas foram induzidas para diferenciação neurogênica; embora houvesse expressão de marcadores neurais primitivos, não expressavam marcadores de neurônios dopaminérgicos completamente 
A

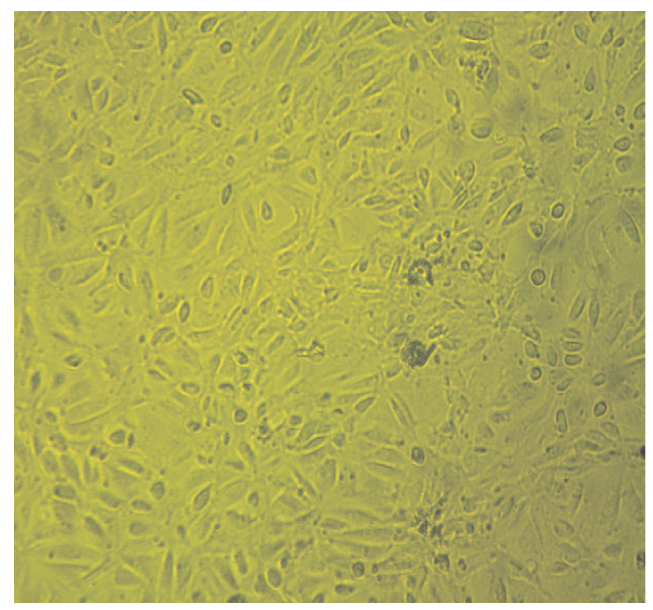

B

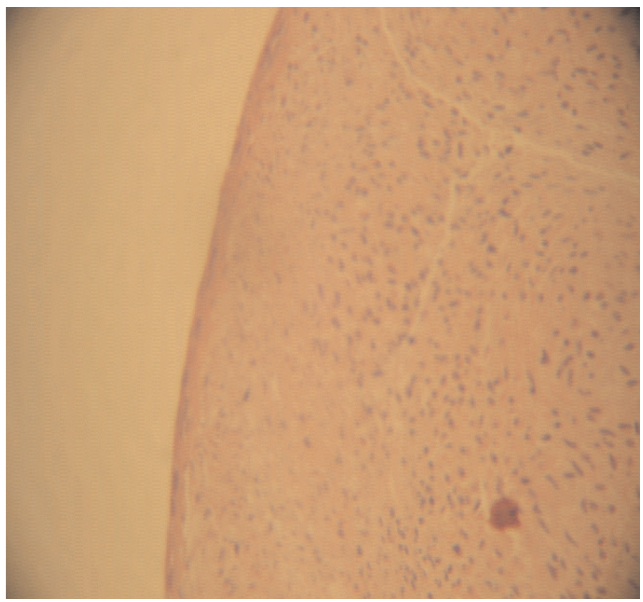

Figura 2. Diferenciação condrogênica (B) de células-tronco de líquido amniótico humano obtido na $20^{a}$ semana de gestação (A)

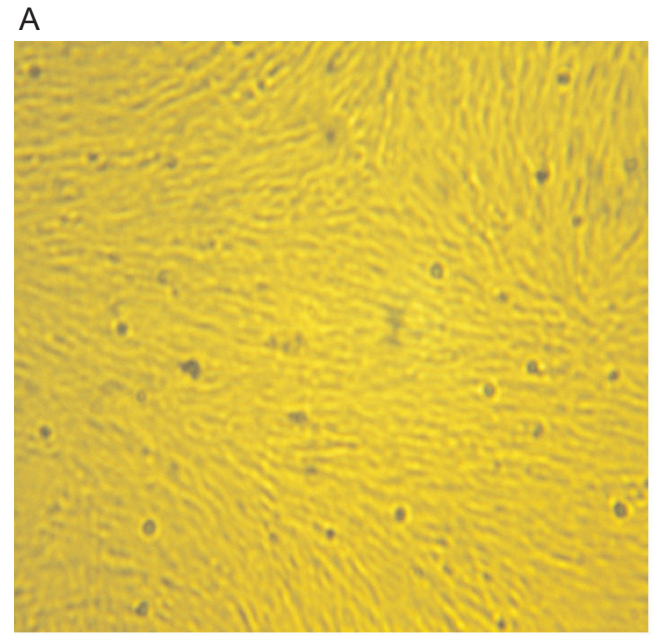

B

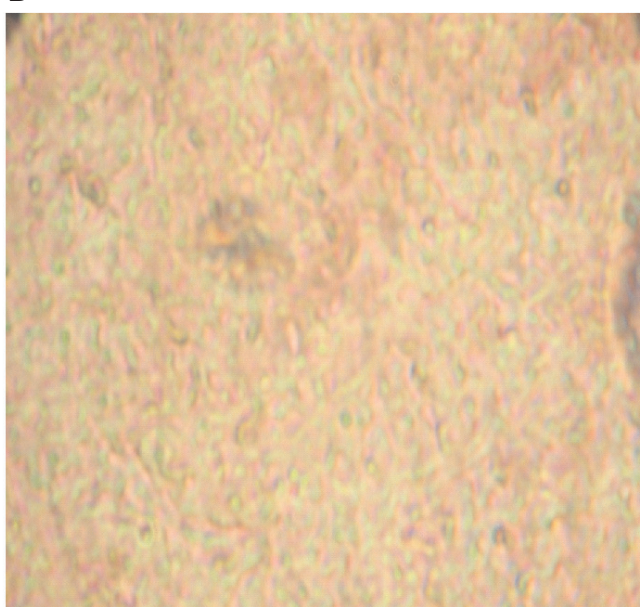

Figura 3. Diferenciação osteogênica ( $B$, células coradas com fosfatase alcalina) de células-tronco de líquido amniótico humano obtido na $20^{\mathrm{a}}$ semana de gestação $(\mathrm{A})$

A

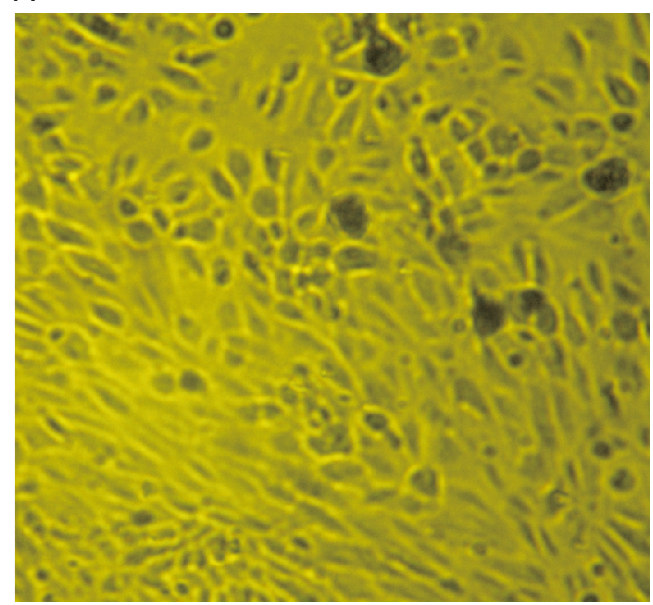

B

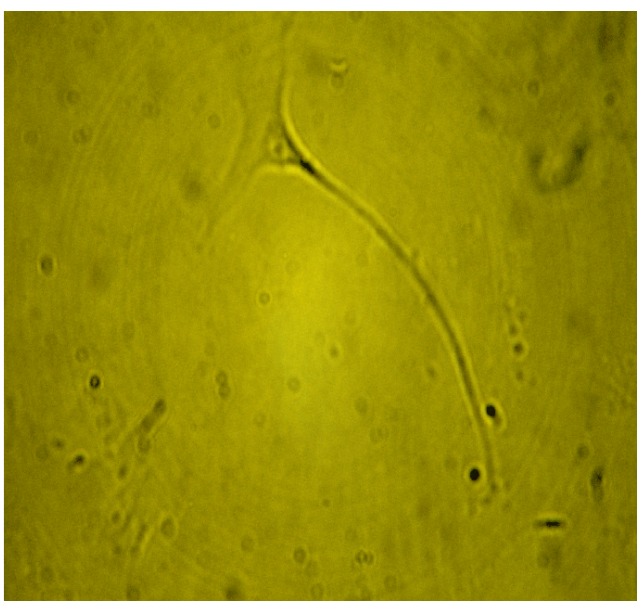

Figura 4. Diferenciação neurogênica $(B)$ de células-tronco de líquido amniótico humano obtido na $20^{\text {a }}$ semana de gestação (A) 
diferenciados, mesmo quando inoculadas em cérebro de modelo animal de doença de Parkinson. ${ }^{68}$

A diferenciação dessas células em hepatócitos apresenta importante aplicação em insuficiência hepática, tendo sido realizado estudo comparando-se com a diferenciação das células-tronco mesenquimais da medula óssea, mostrando superioridade das primeiras neste aspecto, com expressão maior de marcadores específicos hepáticos, além de taxas mais altas de proliferação e autorrenovação celular in vitro. ${ }^{69}$

Tentou-se também aplicação terapêutica em cardiologia, em experimento animal. Em infarto agudo do miocárdio, AFMSCs autólogas foram aplicadas no local de isquemia. Observava-se mudança no padrão de expressão gênica das células inoculadas, com perda dos marcadores de indiferenciação e com permanência dos marcadores de músculos lisos e endoteliais. Não ocorria expressão do marcador de cardiomiócitos, a troponina I. Isso demonstra que as AFMSCs podem se transdiferenciar em células vasculares, mas não comprovadamente em cardiomiócitos. ${ }^{46}$

\section{Considerações Finais}

As AF-MSCs parecem ser uma excelente fonte celular para terapia fetal. A futura utilização dessas células em ensaios clínicos, em humanos, depende de maneiras eficientes de sua obtenção, cultivo e expansão. Quanto mais indiferenciada for uma célula, maior será seu potencial de uso em múltiplas aplicações. Assim, a presença de marcadores de pluripotência e autorrenovação, como o Oct4, SOX-2 e Nanog pode significar a existência de células primitivas no líquido amniótico, indiferenciadas, aumentando ainda mais o interesse nessas células. Não obstante, muito resta a estudar para demonstrar sua capacidade de derivação em diferentes tecidos, mais ainda in vivo, como, por exemplo, em osso e em cartilagem.

As vantagens das AF-MSCs em relação às célulastronco embrionárias (questionamentos éticos e formação de tumores) e em relação às células-tronco adultas (baixa taxa de proliferação e potencial de diferenciação restrito) pode torná-las opção preferencial para a terapia de base celular. Além disso, sua grande capacidade de expansão em cultura, diminuição de imunogenicidade, capacidade de se diferenciar em células da linhagem mesenquimal, parece torná-las a opção mais indicada como fonte celular em engenharia tecidual para construção de tendões autológos e substitutos fibromusculares, para utilização no feto patológico, intraútero, em fase mais tardia da gestação, ou logo após o nascimento. É possível que vejamos logo o desenvolvimento de terapias potenciais usando células-tronco e progenitoras isoladas do líquido amniótico para o tratamento de recém-nascidos com más-formações congênitas ou terapia para adultos utilizando células de líquido amniótico criopreservadas.

\section{Abstract}

Since the first successful isolation and cultivation of human embryonic stem cells about 10 years ago, their use for research and therapy has been constrained by complex ethical considerations as well as by the risk of development of malignancies of undifferentiated embryonic stem cells after transplantation into the patient. Adult stem cells are ethically acceptable and the risk of tumor development is low. However, their differentiation potential and proliferative capacity are limited. About 6 years ago, the discovery of Oct-4 expressing amniotic fluid stem cells, a specific marker of pluripotency, with a high proliferative capacity, and multilineage differentiation potential, initiated a promising field of research. These cells, indeed, have the potential to differentiate into cells of all three embryonic germ layers. They do not form tumors in vivo and do not raise ethical concerns. Further investigation will reveal whether these cells really are an intermediate cell type with advantages over both embryonic and adult stem cells. This article reviews the biological characteristics of amniotic fluid stem cells. Rev. Bras. Hematol. Hemoter. 2009;31(Supl. 1):45-52.

Key words: Stem cell; amniotic fluid; cell differentiation; undifferenciation markers.

\section{Referências Bibliográficas}

1. Gosden CM. Amniotic fluid cell types and culture. Br Med Bull. 1983;39(4):348-54.

2. Torricelli F, Brizzi L, Bernabei PA, Gheri G, Di Lollo S, Nutini L, et al. Identification of hematopoietic progenitor cells in human amniotic fluid before the 12th week of gestation. Ital J Anat Embryol. 1993;98(2):119-26.

3. Streubel B, Martucci-Ivessa G, Fleck T, Bittner RE. In vitro transformation of amniotic cells to muscle cells--background and outlook. Wien Med Wochenschr. 1996;146(9-10):216-7.

4. Erlich H, Bugawan T, Begovich AB, Scharf S, Griffith R, Saiki R, et al. HLA-DR, DQ and DP typing using PCR amplification and immobilized probes. Eur J Immunogenet. 1991;18(1-2): 33-55.

5. Macek M, Hurych J, Rezácová D. Collagen synthesis in long-term cultures of amniotic fluid. Cesk Pediatr. 1973;28(9):478-80.

6. Hurych J, Macek M, Beniac F, Rezácová D. Biochemical characteristics of collagen produced by long term cultivated amniotic fluid cells. Hum Genet. 1976;31(3):335-40.

7. Priest RE, Priest JH, Moinuddin JF, Keyser AJ. Differentiation in human amniotic fluid cell cultures: I: Collagen production. J Med Genet. 1977;14(3):157-62.

8. Whitsett CF, Priest JH, Priest RE, Marion J. HLA typing of cultured amniotic fluid cells. Am J Clin Pathol. 1983;79(2):186-94.

9. Milunsky A, Bender CS. Failure of amniotic-fluid cell growth with toxic tubes. N Engl J Med. 1979;301(1):47-8.

10. Laundon $\mathrm{CH}$, Priest JH, Priest RE. The characterization of hCG regulation in cultured human amniotic fluid cells. Prenat Diagn. 1981;1(4):269-75

11. Prusa AR, Hengstschlager M. Amniotic fluid cells and human stem cell research: a new connection. Med Sci Monit. 2002;8(11): RA253-7.

12. Hoehn H, Salk D. Morphological and biochemical heterogeneity of amniotic fluid cells in culture. Methods Cell Biol. 1982;26:11-34. 
13. Brace RA. Amniotic fluid volume and its relationship to fetal fluid balance: review of experimental data. SSemin Perinatol. $1986 ; 10(2): 103-12$.

14. Seeds AE. Current concepts of amniotic fluid dynamics. Am J Obstet Gynecol. 1980;138(5):575-86.

15. Trounson A. A fluid means of stem cell generation. Nat Biotechnol. 2007;25(1):62-3.

16. Kurjak A, Kirkinen P, Latin V, Ivankovic D. Ultrasonic assessment of fetal kidney function in normal and complicated pregnancies. Am J Obstet Gynecol. 1981;141(3):266-70.

17. Duenhoelter JH, Pritchard JA. Fetal respiration: quantitative measurements of amnionic fluid inspired near term by human and rhesus fetuses. Am J Obstet Gynecol. 1976;125(3):306-9.

18. Olver RE, Strang LB. Ion fluxes across the pulmonary epithelium and the secretion of lung liquid in the foetal lamb. J Physiol. 1974; 241(2):327-57

19. Mescher EJ, Platzker AC, Ballard PL, Kitterman JA, Clements JA, Tooley WH. Ontogeny of tracheal fluid, pulmonary surfactant, and plasma corticoids in the fetal lamb. J Appl Physiol. 1975; 39(6): 1017-21

20. Minei LJ, Suzuki K. Role of fetal deglutition and micturition in the production and turnover of amniotic fluid in the monkey. Obstet Gynecol. 1976;48(2):177-81.

21. Muller F, Dommergues M, Ville Y, Lewin F, Delvalez-Morichon N, Nihoul-Fekete C, et al. Amniotic fluid digestive enzymes: diagnostic value in fetal gastrointestinal obstructions. Prenat Diagn. 1994; 14(10):973-9.

22. De Coppi P, Bartsch G Jr, Siddiqui MM, Xu T, Santos CC, Perin L, et al. Isolation of amniotic stem cell lines with potential for therapy. Nat Biotechnol. 2007;25(1):100-6

23. Kaviani A, Perry TE, Dzakovic A, Jennings RW, Ziegler MM, Fauza DO. The amniotic fluid as a source of cells for fetal tissue engineering. J Pediatr Surg. 2001;36(11):1662-5.

24. Kaviani A, Guleserian K, Perry TE, Jennings RW, Ziegler MM, Fauza DO. Fetal tissue engineering from amniotic fluid. J Am Coll Surg. 2003;196(4):592-7.

25. Tsai MS, Hwang SM, Tsai YL, Cheng FC, Lee JL, Chang YJ. Clonal amniotic fluid-derived stem cells express characteristics of both mesenchymal and neural stem cells. Biol Reprod. 2006; 74(3):545-51.

26. Prusa AR, Marton E, Rosner M, Bettelheim D, Lubec G, Pollack A, et al. Neurogenic cells in human amniotic fluid. Am J Obstet Gynecol. 2004;191(1):309-14.

27. Amniotic fluid harbours multipotent stem cells. Reprod Biomed Online. 2007;14(3):395

28. Kim J, Lee Y, Kim H, Hwang KJ, Kwon HC, Kim SK, et al. Human amniotic fluid-derived stem cells have characteristics of multipotent stem cells. Cell Prolif. 2007;40(1):75-90.

29. You Q, Cai L, Zheng J, Tong X, Zhang D, Zhang Y. Isolation of human mesenchymal stem cells from third-trimester amniotic fluid. Int J Gynaecol Obstet. 2008;103(2):149-52.

30. Woodbury D, Kramer BC, Reynolds K, Marcus AJ, Coyne TM, Black IB. Long-term cryopreserved amniocytes retain proliferative capacity and differentiate to ectodermal and mesodermal derivatives in vitro. Mol Reprod Dev. 2006;73(11):1463-72.

31. In 't Anker PS, Scherjon SA, Kleijburg-van der Keur C, Noort WA, Claas FH, Willemze R, et al. Amniotic fluid as a novel source of mesenchymal stem cells for therapeutic transplantation. Blood. $2003 ; 102(4): 1548-9$.

32. Kunisaki SM, Fuchs JR, Steigman SA, Fauza DO. A comparative analysis of cartilage engineered from different perinatal mesenchyma progenitor cells. Tissue Eng. 2007;13 (11): 2633-44
33. Roubelakis MG, Pappa KI, Bitsika V, Zagoura D, Vlahou A, Papadaki $\mathrm{HA}$, et al. Molecular and proteomic characterization of human mesenchymal stem cells derived from amniotic fluid: comparison to bone marrow mesenchymal stem cells. Stem Cells Dev. 2007;16(6):931-52

34. In 't Anker PS, Scherjon SA, Kleijburg-van der Keur C, de GrootSwings GM, Claas FH, et al. Isolation of mesenchymal stem cells of fetal or maternal origin from human placenta. Stem Cells. $2004 ; 22(7): 1338-45$

35. Pittenger MF, Mackay AM, Beck SC, Jaiswal RK, Douglas R, Mosca JD, et al. Multilineage potential of adult human mesenchymal stem cells. Science. 1999;284(5411):143-7.

36. Tsai MS, Lee JL, Chang YJ, Hwang SM. Isolation of human multipotent mesenchymal stem cells from second-trimester amniotic fluid using a novel two-stage culture protocol. Hum Reprod. 2004;19(6):1450-6.

37. Lee OK, Kuo TK, Chen WM, Lee KD, Hsieh SL, Chen TH. Isolation of multipotent mesenchymal stem cells from umbilical cord blood. Blood. 2004;103(5):1669-75.

38. Kunisaki SM, Armant M, Kao GS, Stevenson K, Kim H, Fauza DO. Tissue engineering from human mesenchymal amniocytes: a prelude to clinical trials. J Pediatr Surg. 2007;42(6):974-9.

39. Steigman SA, Armant M, Bayer-Zwirello L, Kao GS, Silberstein L, Ritz J, et al. Preclinical regulatory validation of a 3-stage amniotic mesenchymal stem cell manufacturing protocol. J Pediatr Surg. 2008;43(6):1164-9.

40. Wobus AM, Boheler KR. Embryonic stem cells: prospects for developmental biology and cell therapy. Physiol Rev. 2005; 85(2):635-78.

41. Prusa AR, Marton E, Rosner M, Bernaschek G, Hengstschläger M. Oct-4-expressing cells in human amniotic fluid: a new source for stem cell research? Hum Reprod. 2003;18(7):1489-93.

42. Kunisaki SM, Fuchs JR, Kaviani A, Oh JT, LaVan DA, Vacanti JP, et al. Diaphragmatic repair through fetal tissue engineering: a comparison between mesenchymal amniocyte- and myoblast-based constructs. J Pediatr Surg. 2006;41(1):34-9.

43. Martin FH, Suggs SV, Langley KE, Lu HS, Ting J, Okino KH, et al. Primary structure and functional expression of rat and human stem cell factor DNAs. Cell. 1990;63(1):203-11.

44. Takeda J, Seino S, Bell GI. Human Oct3 gene family: cDNA sequences, alternative splicing, gene organization, chromosomal location, and expression at low levels in adult tissues. Nucleic Acids Res. 1992;20(17):4613-20.

45. Shamblott MJ, Axelman J, Littlefield JW, Blumenthal PD, Huggins GR, Cui Y, et al. Human embryonic germ cell derivatives express a broad range of developmentally distinct markers and proliferate extensively in vitro. Proc Natl Acad Sci U S A. 2001;98(1):113-8.

46. Sartore S, Lenzi M, Angelini A, Chiavegato A, Gasparotto L, De Coppi $\mathrm{P}$, et al. Amniotic mesenchymal cells autotransplanted in a porcine model of cardiac ischemia do not differentiate to cardiogenic phenotypes. Eur J Cardiothorac Surg. 2005;28(5):677-84.

47. Zangrossi S, Marabese M, Broggini M, Giordano R, D'Erasmo M, Montelatici E, et al. Oct-4 expression in adult human differentiated cells challenges its role as a pure stem cell marker. Stem Cells. 2007;25(7):1675-80.

48. Xi R, Xie T. Stem cell self-renewal controlled by chromatin remodeling factors. Science. 2005;310(5753):1487-9.

49. Roobrouck VD, Ulloa-Montoya F, Verfaillie CM. Self-renewal and differentiation capacity of young and aged stem cells. Exp Cell Res. 2008;314(9):1937-44.

50. Sadler TW. Langman Embriologia Médica. $9^{\mathrm{a}}$ ed. Editora Guanabara Koogan, Rio de Janeiro, RJ. Pp.131-137, 2005 
51. Prior HM, Walter MA. SOX genes: architects of development. Mol Med. 1996;2(4):405-12.

52. Alberio R, Campbell KH, Johnson AD. Reprogramming somatic cells into stem cells. Reproduction. 2006;132(5):709-20.

53. Darr H, Mayshar Y, Benvenisty N. Overexpression of NANOG in human ES cells enables feeder-free growth while inducing primitive ectoderm features. Development. 2006;133(6):1193-201.

54. Nichols J, Zevnik B, Anastassiadis K, Niwa H, Klewe-Nebenius D, Chambers I, et al. Formation of pluripotent stem cells in the mammalian embryo depends on the POU transcription factor Oct4. Cell. 1998;95(3):379-91.

55. Schöler HR, Ruppert S, Suzuki N, Chowdhury K, Gruss P. New type of POU domain in germ line-specific protein Oct-4. Nature. 1990;344(6265):435-9.

56. Pan GJ, Chang ZY, Schöler HR, Pei D. Stem cell pluripotency and transcription factor Oct4. Cell Res. 2002;12(5-6):321-9.

57. Pan G, Qin B, Liu N, Schöler HR, Pei D. Identification of a nuclear localization signal in OCT4 and generation of a dominant negative mutant by its ablation. J Biol Chem. 2004;279(35): 37013-20.

58. Boyer LA, Lee TI, Cole MF, Johnstone SE, Levine SS, Zucker JP, et al. Core transcriptional regulatory circuitry in human embryonic stem cells. Cell. 2005;122(6):947-56.

59. Chambers I, Colby D, Robertson M, Nichols J, Lee S, Tweedie S, et al. Functional expression cloning of Nanog, a pluripotency sustaining factor in embryonic stem cells. Cell. 2003;113(5):643-55.

60. Niwa H, Miyazaki J, Smith AG. Quantitative expression of Oct-3/ 4 defines differentiation, dedifferentiation or self-renewal of ES cells. Nat Genet. 2000;24(4):372-6.

61. Mitsui K, Tokuzawa Y, Itoh H, Segawa K, Murakami M, Takahashi $\mathrm{K}$, et al. The homeoprotein Nanog is required for maintenance of pluripotency in mouse epiblast and ES cells. Cell. 2003; 113 (5):631-42.

62. Takahashi K, Yamanaka S. Induction of pluripotent stem cells from mouse embryonic and adult fibroblast cultures by defined factors. Cell. 2006;126(4):663-76.
63. Jaenisch R, Young R. Stem cells, the molecular circuitry of pluripotency and nuclear reprogramming. Cell. 2008; 132 (4): 567-82.

64. Qin D, Li W, Zhang J, Pei D. Direct generation of ES-like cells from unmodified mouse embryonic fibroblasts by Oct $4 / \mathrm{Sox} 2 / \mathrm{Myc} /$ Klf4. Cell Res. 2007;17(11):959-62.

65. Yu J, Vodyanik MA, Smuga-Otto K, Antosiewicz-Bourget J, Frane $\mathrm{JL}$, Tian S, et al. Induced pluripotent stem cell lines derived from human somatic cells. Science. 2007;318(5858):1917-20.

66. Deb KD, Sarda K. Human embryonic stem cells: preclinical perspectives. J Transl Med. 2008;6:7.

67. Kunisaki SM, Jennings RW, Fauza DO. Fetal cartilage engineering from amniotic mesenchymal progenitor cells. Stem Cells Dev. 2006; 15(2):245-53.

68. Donaldson AE, Cai J, Yang M, Iacovitti L. Human Amniotic Fluid Stem Cells do not Differentiate into Dopamine Neurons In Vitro or After Transplantation In Vivo. Stem Cells Dev. 2008. [Epub ahead of print].

69. Zheng YB, Gao ZL, Xie C, Zhu HP, Peng L, Chen JH, et al. Characterization and hepatogenic differentiation of mesenchymal stem cells from human amniotic fluid and human bone marrow: a comparative study. Cell Biol Int. 2008;32(11):1439-48.

Avaliação: O tema apresentado consta da pauta elaborada pelo editor, Professor Milton Artur Ruiz, e coeditores deste suplemento, Professores Sergio Paulo Bydlowski e Adriana Seber.

Conflito de interesse: não declarado

Recebido: 20/04/2009

Aceito: 22/04/2009 